\title{
Closing the Circle on the Discovery of Genes Encoding Hrp Regulon Members and Type III Secretion System Effectors in the Genomes of Three Model Pseudomonas syringae Strains
}

\author{
Magdalen Lindeberg, ${ }^{1}$ Samuel Cartinhour, ${ }^{2}$ Christopher R. Myers,${ }^{3}$ Lisa M. Schechter, ${ }^{1}$ \\ David J. Schneider, ${ }^{2}$ and Alan Collmer ${ }^{1}$ \\ ${ }^{1}$ Department of Plant Pathology, Cornell University, Ithaca, NY 14853, U.S.A.; ${ }^{2}$ U. S. Department of Agriculture-Agricultural \\ Research Service, Ithaca, NY 14853, U.S.A.; ${ }^{3}$ Cornell Theory Center, Cornell University, Ithaca, NY 14853, U.S.A.
}

Submitted 22 August 2006. Accepted 15 September 2006.

Pseudomonas syringae strains translocate large and distinct collections of effector proteins into plant cells via the type III secretion system (T3SS). Mutations in T3SS-encoding hrp genes are unable to elicit the hypersensitive response or pathogenesis in nonhost and host plants, respectively. Mutations in individual effectors lack strong phenotypes, which has impeded their discovery. $P$. syringae effectors are designated Hop (Hrp outer protein) or Avr (avirulence) proteins. Some Hop proteins are considered to be extracellular T3SS helpers acting at the plant-bacterium interface. Identification of complete sets of effectors and related proteins has been enabled by the application of bioinformatic and high-throughput experimental techniques to the complete genome sequences of three model strains: $P$. syringae pv. tomato DC3000, $P$. syringae pv. phaseolicola 1448A, and $P$. syringae pv. syringae $\mathbf{B 7 2 8 a}$. Several recent papers, including three in this issue of Molecular Plant-Microbe Interactions, address the effector inventories of these strains. These studies establish that active effector genes in $P$. syringae are expressed by the HrpL alternative sigma factor and can be predicted on the basis of cis Hrp promoter sequences and N-terminal amino-acid patterns. Among the three strains analyzed, $P$. syringae pv. tomato DC3000 has the largest effector inventory and $P$. syringae pv. syringae B728a has the smallest. Each strain has several effector genes that appear inactive. Only five of the $\mathbf{4 6}$ effector families that are represented in these three strains have an active member in all of the strains. Web-based community resources for managing and sharing growing information on these complex effector arsenals should help future efforts to understand how effectors promote $\boldsymbol{P}$. syringae virulence.

Additional keywords: ECF sigma factor, functional genomics, microarrays.

Pseudomonas syringae represents a group of economically important bacterial pathogens noted for their diverse interactions

Corresponding author: Alan Collmer; E-mail: arc2@cornell.edu

* The $\boldsymbol{e}$-Xtra logo stands for "electronic extra" and indicates the HTML abstract available on-line contains a supplemental table not included in the print edition. with plants (Hirano and Upper 2000). Pathovars of $P$. syringae vary in their capacity for epiphytic survival, the nature of the symptoms they elicit, and their host range. The molecular basis for these interactions appears complex because it is controlled by the interplay of several classes of factors and each class can have many members with overlapping functions. Classes of virulence factors include phytotoxins, phytohormones, adhesins, cell-wall degrading enzymes, and most importantly, effector proteins translocated into plants by the type III secretion system (T3SS) (Buell et al. 2003). The T3SS is also known as the Hrp system because it is encoded by hrp genes that are required for $P$. syringae strains to elicit the hypersensitive response (HR) in nonhosts or to be pathogenic in hosts. Also modulating bacterium-plant interactions are classes of factors contributing to plant defense, including microbe-associated molecular patterns, which are produced by the bacteria and corresponding pattern-recognition proteins that are produced by the plant, as well as resistance proteins that recognize effectors or their activity within plant cells (Alfano and Collmer 2004; Chisholm et al. 2006; Grant et al., in press; Mudgett 2005; Nomura et al. 2005). Identifying the complete set of factors in each class is prerequisite to deconvoluting the molecular basis and evolution of $P$. syringae-plant pathosystems.

The study of $P$. syringae virulence has been revolutionized by genomics, beginning with the publicly available draft sequence and then the complete sequence of $P$. syringae pv. tomato DC3000 (Buell et al. 2003), followed by the complete sequences of $P$. syringae pv. syringae $\mathrm{B} 728 \mathrm{a}$ and $P$. syringae $\mathrm{pv}$. syringae 1448A (Feil et al. 2005; Joardar et al. 2005). These three strains represent an attractive set for functional genomics. They have different host ranges and pathogenic strategies and they represent each of the three major phylogenetic clades that contain the 50 or so pathovars within this species (Sarkar and Guttman 2004; Sawada et al. 1999). Each strain provides a different window into the complex interactions of $P$. syringae with plants. $P$. syringae pv. tomato DC3000 causes bacterial speck of Arabidopsis and tomato and has emerged as a model for studying basic virulence mechanisms (Preston 2000; Quirino and Bent 2003). P. syringae pv. phaseolicola causes halo blight of bean, an important disease in several developing countries, and is a model for studying the nature and variability of racecultivar interactions (Jackson et al. 1999; Pitman et al. 2005). $P$. syringae pv. syringae, which causes brown spot of bean, is a 
model for studying bacterial epiphytic growth and behavior in the field (Hirano and Upper 2000; Marco et al. 2005; Monier and Lindow 2003).

Type III effectors provided the ideal demonstration case for applying functional genomics to the study of $P$. syringae virulence because of the collective importance and large number of these proteins. Consequently, several labs around the world have participated in genome-enabled identification of type III effectors in P. syringae. Two previous reviews describe the first phase in this effort, which was based on draftphase $P$. syringae pv. tomato DC3000 genome sequences (Collmer et al. 2002; Greenberg and Vinatzer 2003). This short review focuses on several recent papers, including three in this issue, that exploit complete genome sequences to explore the Hrp regulons and effector inventories of $P$. syringae pv. tomato DC3000, P. syringae pv. phaseolicola 1448A, and $P$. syringae $\mathrm{pv}$. syringae $\mathrm{B} 728 \mathrm{a}$. These papers report a differential fluorescence induction (DFI) screen for effectors in D3000 and 1448A (Chang et al. 2005), identification and validation of multiple effectors in B728a (Vinatzer et al. 2005), microarray analyses of the Hrp regulon in DC3000 (Ferreira et al. 2006; Lan et al. 2006), multiple approaches to a complete inventory of the effector genes of DC3000 (Schechter et al. 2006; Vinatzer et al. 2005), and the facile use of bioinformatic methods to comprehensively identify effector genes in DC3000 and 1448A (Ferreira et al. 2006; Vencato et al. 2006). Importantly, these papers illustrate the power of functional genomics in the study of complex virulence systems and highlight the value of curated, web-accessible, community datasets as a foundation for future work.

\section{The bioinformatic-enabled candidate gene approach permits identification of complete sets of virulence genes without a prior requirement for evident phenotypes.}

The development of transposon mutagenesis tools in the mid-1980s provided a method for tagging and cloning virulence genes that was broadly applicable but limited by the requirement for a robust phenotype. Transposon-tagging easily identified the $h r p$ genes encoding the T3SS in P. syringae because of their strong phenotypes in inoculated plants, but it failed to identify effector genes because they lacked such a phenotype. However, a sample set of effector genes had been identified in the pregenomics era on the basis of gain-offunction assays for avirulence in inoculated plants carrying cognate resistance $(R)$ genes or for the ability of the encoded proteins to travel the T3SS pathway. Effectors identified by these assays were given Avr (avirulence) or Hop (Hrp outer protein) designations, respectively (Lindeberg et al. 2005). The bioinformatic-enabled candidate gene approach allowed patterns associated with this sample set to be applied to the complete genome of $P$. syringae pv. tomato DC3000 in search of all potential avr/hop effector genes (Fig. 1). This approach involves iterative cycles of pattern recognition and pattern-based genome searching followed by candidate validation. Genes in the initial sample set were characteristically preceded by "Hrp box" promoter sequences that are responsive to the HrpL alternative sigma factor (Fouts et al. 2002; Guttman et al. 2002; Zwiesler-Vollick et al. 2002). As the set of validated effector proteins grew, patterns associated with their $\mathrm{N}$-terminal 50 amino acids were recognized and were then used as an additional search tool (Guttman et al. 2002; Petnicki-Ocwieja et al. 2002).

The use of promoter sequences and targeting-associated patterns to search the draft genome of DC3000 demonstrated that these patterns could identify many effector candidates, and subsequent testing validated several of these (Collmer et al. 2002; Greenberg and Vinatzer 2003; Schechter et al.
2004; Vinatzer et al. 2005). However, many questions remained. Can bioinformatic methods, such as hidden Markov modeling, predict all HrpL-response promoters? Are all active effector genes in $P$. syringae preceded by Hrp promoters? Do all effector proteins possess targeting-associated patterns (or linkage with chaperones that are characteristic of some effectors or both)? Can these bioinformatic features be used to comprehensively and selectively identify all of the active effectors in any $P$. syringae strain for which there is a genome sequence?

There are several reasons why these questions persisted. First, there are multiple variations in validated Hrp promoter sequences but the limits of permissible variation have not been determined. Second, the process by which T3SS substrates are targeted to the pathway is still poorly understood and an actual function for the $P$. syringae targeting-associated patterns awaits demonstration. Third, in many other T3SS-dependent plant and animal pathogens, some effector genes are regulated independently of the T3SS genes and some effectors have $\mathrm{N}$-termini that are completely devoid of the patterns associated with $P$. syringae T3SS substrates. This raises the possibility that these patterns can be used to find only a subset of the $P$. syringae effectors. Furthermore, as the inventory of candidate effectors grows, new concerns arise regarding the possibility of false positives or of effectors that are real but are not actively deployed by the studied strain. Resolving these issues required genome-enabled, highthroughput experimental approaches that identify Hrp regulon members and effectors independently of promoter and targeting-associated patterns. As will be discussed next, several of the papers highlighted in this short review achieve that end and thereby permit rigorous assessment of the bioinformatic approach.

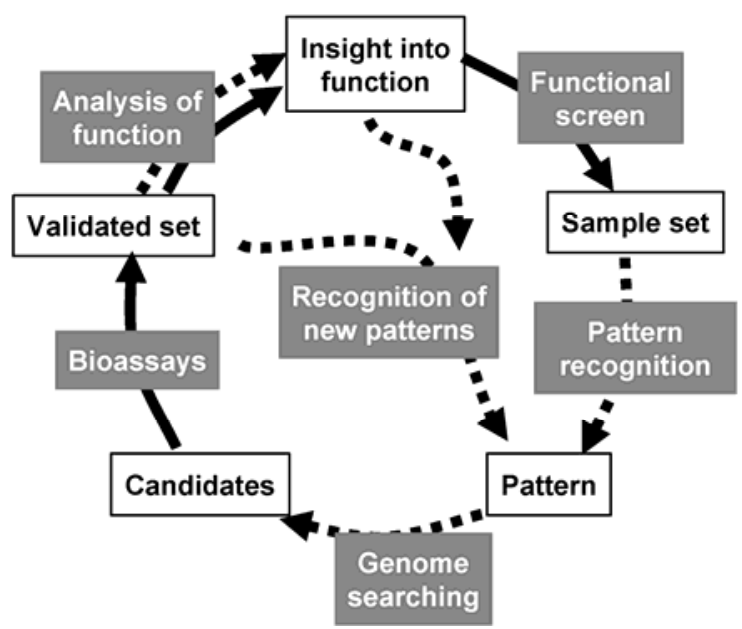

Fig. 1. The iterative, bioinformatic/experimental, pattern-based approach to finding and validating candidate genes in multifactorial systems in bacterial genomes. The representative cycle of experimental steps (solid arrows) and bioinformatic steps (dashed arrows) was used to identify type III effector genes in Pseudomonas syringae pv. tomato DC3000 and then $P$. syringae pv. phaseolicola $1448 \mathrm{~A}$ and $P$. syringae $\mathrm{pv}$. syringae $\mathrm{B} 728 \mathrm{a}$. In the first step, gain-of-function screens for avirulence phenotypes yielded a sample set of $P$. syringae effectors. Hrp box promoter patterns were discerned upstream of these genes. Hidden Markov modeling of an expanded sample set of $P$. syringae pv. tomato DC3000 Hrp promoters enabled comprehensive searching of the genome for candidate effector genes. Translocation bioassays validated effectors. New patterns associated with the N-terminal amino acids of validated effectors were discerned and were used in combination with Hrp promoters to efficiently identify high-probability effector candidates. Further analysis of large sets of effectors can yield insights into effector evolution, active domains, and new patterns underlying functions in pathogenesis. 
Comprehensive experimental identification of HrpL-responsive genes in $P$. syringae pv. tomato DC3000 validates the bioinformatic approach to Hrp promoter identification.

The transfer of $P$. syringae to a minimal medium that mimics plant intercellular fluids triggers a regulatory cascade involving the sequential action of genes encoding the HrpRS $\sigma 54$ enhancer binding proteins, the HrpL extracytoplasmic factor (ECF) sigma factor, and finally, the T3SS machinery and effectors. A review in this Focus Section provides more background on factors controlling HrpL activation (Tang et al. 2006). The emphasis here is on effectors and other genes that are activated by HrpL. Two approaches have been employed to comprehensively identify such genes using highthroughput experimental methods. Chang et al. (2005) used DFI and a fluorescence-activated cell sorter (FACS) to iden- tify operon fusions that are upregulated following inducible overexpression of HrpL. Sequencing of many clones following FACS enrichment for HrpL activation resulted in a nearsaturation screen. Alternatively, Lan et al. (2006) and Ferreira et al. (2006) used microarrays to identify genes that are differentially expressed in minimal medium in wild-type DC3000 when compared with hrpL mutant strains. The three reports yield congruent results for strongly expressed T3SS machinery and effector genes, but differences in the studies yield additional insights into the HrpL regulon. For example, the DFI screen was also performed on P. syringae pv. phaseolicola, which enabled HrpL regulon comparisons that are discussed below. Lan et al. (2006) included a microarray analysis of genes that are activated by HrpRS, and Ferreira et al. (2006) featured a kinetic analysis of HrpL-dependent gene activation.

Table 1. Genes encoding effectors and related proteins in Pseudomonas syringae pv. tomato (Pto) DC3000, P. syringae pv. phaseolicola (Pph) 1448A, and $P$. syringae pv syringae $\left(P\right.$ sy) $\mathrm{B} 728 \mathrm{a}^{\mathrm{a}}$

\begin{tabular}{|c|c|c|c|c|c|c|c|c|c|}
\hline Family/subfamily ${ }^{2}$ & Previous names $^{\mathrm{b}}$ & $P t o$ DC3000 ${ }^{\mathrm{c}}$ & Pph 1448A & Psy B728a & Family/subfamily $^{a}$ & Previous names ${ }^{b}$ & $P t o$ DC3000 ${ }^{\mathrm{c}}$ & Pph 1448A & Psy B728a \\
\hline$a v r B 2$ & avrC & & \begin{tabular}{|l|} 
PSPPH_A0120 \\
\end{tabular} & & hopYl & & PSPTO_0061 & & \\
\hline$a v r B 3$ & & & & Psyr_1219 & hopZ3 & & & & Psyr_1224 \\
\hline avrB4-I & & & PSPPH_3028 & & hopAAl & & & & Psyr_1183 \\
\hline avrB4-2 & & & PSPPH_0784 & & hopAAl' & & & PSPPH_1263 & \\
\hline avrDI & avrD & & $\begin{array}{l}\text { PSPPH_A0113 } \\
\end{array}$ & & hopAAl-1 & & PSPTO1372 & & \\
\hline avrEl & avrE & PSPTO_1377 & PSPPH_1268 & Psyr_1188 & hopAAI-2 & & PSPTO_4718 & & \\
\hline avrPtol & avrPto & PSPTO_4001 & & Psyr_4919 & hopABI & VirPphA & & PSPPH_A0127 & $\begin{array}{l}\text { Psyr_4659 } \\
\text { Psy }\end{array}$ \\
\hline avrRpml & & & & Psyr_0738 & hopAB2 & avrPtoB & PSPTO_3087 & & \\
\hline avrRps 4 & & & PSPPH A0087 & & hopAB3' & & & PSPPH_2294 & \\
\hline hopAl & hrmA, hopPsyA & PSPTO_5354 & & & hopADI & & PSPTO_4691 & & \\
\hline hopBI & & PSPTO_1406 & & & hopAEI & & & PSPPH_4326 & Psyr_4269 \\
\hline hopCl & avrPpiC2 & PSPTO_0589 & & & hopAFl & & PSPTO_1568 & PSPPH_1443 & Psyr_3813 \\
\hline hopDI & avrPphD & PSPTO_0876 & PSPPH_A0010 & & hopAGl & & & & $\begin{array}{l}\text { Psyr_0778 } \\
\end{array}$ \\
\hline hopD::IS52 & & PSPTO_4724 & & & hopAG:ISPssy & & PSPTO_0901 & & \\
\hline hopEI & & PSPTO_4331 & & & hopAHI & & PSPTO_0905 & & $\begin{array}{l}\text { Psyr_0779 } \\
\end{array}$ \\
\hline hopF2 & avrPphF & PSPTO_0502 & & & hopAH2 & & & PSPPH_3036 & Psyr_3123 \\
\hline hopF3 & & & PSPPH_3498 & & hopAH2-I & & PSPTO_3292 & & \\
\hline hopGI & & $\begin{array}{l}\text { PSPTO_4727 } \\
\end{array}$ & $\begin{array}{l}\text { PSPPH_0767 } \\
\end{array}$ & & hорAH2-2 & & PSPTO_3293 & & \\
\hline hopHI & & PSPTO_0588 & & 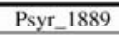 & hopAII & & PSPTO_0906 & & \\
\hline hopH::ISPsy4 & & PSPTO_5623 & & & hopAll' & & & & Psyr_0780 \\
\hline hopll & & PSPTO_4776 & PSPPH_4366 & $\begin{array}{l}\text { Psyr_4326 } \\
\end{array}$ & hopAMI-I & avrPpiBI & PSPTO_1022 & & \\
\hline hopKI & & PSPTO_0044 & & & hopAMI-2 & avrPpiB2 & PSPTO_A0005 & & \\
\hline hopMI & & PSPTO_1375 & & Psyr_1186 & hopANI & Ipx53 & PSPTO_5061 & PSPPH_0456 & $\begin{array}{l}\text { Psyr_0465 } \\
\end{array}$ \\
\hline hopMI' & & & PSPPH_1266 & & hopAOI & avrPphD2 & PSPTO_4722 & & \\
\hline hopNI & & PSPTO_1370 & & & hopAQI & & PSPTO_4703 & & \\
\hline hopOl-l & & PSPTO_A0018 & & & hopASI & & & PSPPH_4736 & \\
\hline hopOI-2 & & PSPTO_4594 & & & hopASI' & & PSPTO_0474 & & \\
\hline hopOI-3' & & PSPTO_4592 & & & hopATI & & & PSPPH_5225 & \\
\hline hopQI & & & \begin{tabular}{|l|} 
PSPPH_A0012 \\
\end{tabular} & & hopATI' & & PSPTO_5618 & & \\
\hline hopQl-I & & PSPTO_0877 & & & hopAUI & & & PSPPH_A0031 & \\
\hline hopQl-2 & & PSPTO_4732 & & & hopAVI & & & PSPPH_A0056 & \\
\hline hopRI & & PSPTO_0883 & PSPPH_0171 & & hopAWI & & & PSPPH_A0122 & \\
\hline hopSl::ISPssy & & PSPTO_4597 & & & Harpins. & filus-associated prote & ins, and other car & ndidate T3SS hel & \\
\hline hopS2 & & PSPTO_4588 & & & hrpAI & & PSPTO_1381 & & \\
\hline hopTl-1 & & PSPTO_A0019 & & & hrpA2 & & & PSPPH_1272 & Psyr_1192 \\
\hline hopTl-2 & & \begin{tabular}{|l|} 
PSPTO_4593 \\
\end{tabular} & & & hrpKI & & PSPTO_1405 & PSPPH_1295 & 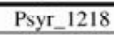 \\
\hline hopT2 & & PSPTO_4590 & & & hrpWI & & PSPTO_1373 & PSPPH_1264 & Psyr_1184 \\
\hline hopUI & & $\begin{array}{l}\text { PSPTO_0501 } \\
\end{array}$ & & & hrpZI & & PSPTO_1382 & PSPPH_1273 & Psyr_1193 \\
\hline hopVI & & PSPTO_4720 & PSPPH_2351 & & hopPl & & PSPTO_2678 & & \\
\hline hopWI-I & & & \begin{tabular}{|l|} 
PSPPH_A0009 \\
\end{tabular} & & hopAJI & & PSPTO_0852 & PSPPH_0763 & \\
\hline hopWI-2 & & & PSPPH_A0075 & & hopAKI & & PSPTO_4101 & PSPPH_1424 & Psyr_3839 \\
\hline hopXI & avrPphE & PSPTO_A0012 & PSPPH_1296 & Psyr_1220 & & & & & \\
\hline
\end{tabular}

${ }^{\text {a }}$ Hop gene families are listed according to the names assigned under the new Hop nomenclature, with family and subfamily assignments based on the phylogenetic distances calculated in MEGA2.1 from CLUSTAL sequence alignments (Lindeberg et al. 2005). Heavy lines are used to group subfamilies within a single family. The nature and source of data supporting the hop designations can be found in the Hop Database at the Pseudomonas-Plant Interaction website. Information on the hopJ, hopL, hopAC, and hopAP families is also found there, though they are omitted from this list since no validated members are HrpL-regulated and T3SS substrates.

${ }^{\mathrm{b}}$ In cases where hop names replace previously assigned names having functional significance, the earlier common names are indicated. A comprehensive list of previously assigned names for all hops listed can be found in the Hop Database at the Pseudomonas-Plant Interaction website. Note that avrPto and avrPtoB continue to be widely used because of extensive precedence in the literature.

${ }^{c}$ Presence of hop genes in the three P. syringae pathovars is indicated by the locus tag for the gene in question. Locus tags in bold indicate plasmid-borne genes. Locus tags are colored as follows: pink, experimental evidence supports HrpL-dependent regulation and passage through the T3SS; blue, bioinformatic and/or experimental evidence argues against HrpL-dependent expression and/or passage through the T3SS or gene is disrupted in 5' region; yellow, experimental evidence supports HrpL-dependent regulation or passage through the T3SS, but evidence is either incomplete or contradictory; white, HrpL-dependent regulation and passage through the T3SS predicted but not experimentally evaluated. 
Only half of the 129 genes that are activated by HrpRS are activated by HrpL, and five of the genes that are activated exclusively by HrpRS are transcriptional regulators (Lan et al. 2006). Furthermore, several of the genes or operons that are activated by HrpL lack Hrp promoters (Ferreira et al. 2006; Lan et al. 2006). Thus, HrpRS and HrpL appear to control multiple, candidate, virulence-related subsidiary regulons. In contrast to genes that are directly regulated by HrpL, those indirectly regulated appear to be more affected by culture conditions or HrpL expression levels. For example, overexpression of HrpL in repressive media enhanced the expression of $c f l$ genes directing biosynthesis of the phytotoxin coronatine (Chang et al. 2005; Fouts et al. 2002), but mutants lacking HrpL were unaffected in their expression of these genes in minimal media (Ferreira et al. 2006). The conditions and circuits controlling the ancillary regulons associated with HrpRS and HrpL are a high priority for future study, but the focus here is on the genes preceded by HrpL-responsive Hrp promoters, which we refer to as the HrpL regulon.

Hierarchical clustering based on expression kinetics revealed that the most rapidly activated genes in the HrpL regulon control extracellular components of the T3SS, such as the HrpA pilus protein, the HrpK putative translocator, and harpins, which may have a role as extracellular T3SS helpers (Ferreira et al. 2006). The rapid activation of similar genes in $P$. syringae pv. phaseolicola was previously observed using real-time polymerase chain reaction (PCR) (Thwaites et al. 2004). Although effectors form the largest class of genes preceded by Hrp promoters, it is important to note that nearly twenty Hrp promoter-driven genes have no apparent T3SS-related function (Ferreira et al. 2006; Lan et al. 2006). PSPTO2105 (ApbEfamily protein) and PSPTO0834 (alcohol dehydrogenase) represent two of these genes, and mutations in each reduce the growth of $P$. syringae pv. tomato DC3000 in Arabidopsis leaves (Vencato et al. 2006). Learning how these proteins contribute to bacterial growth in planta and whether the products of other non-T3SS genes in the HrpL regulon have a similar role is another important target for future research.

Many of the P. syringae pv. tomato DC3000 Hrp promoters that were experimentally validated by DFI and microarray analyses had been predicted by hidden Markov modeling, based on a preliminary training set of validated Hrp promoters (Fouts et al. 2002). The much larger set of validated Hrp promoters generated by microarray analysis enabled Ferreira et al. (2006) to rigorously assess the predictive value of both hidden Markov modeling and weight matrix modeling and to use Gibbs sampling to look for additional regulatory sequences upstream of HrpL-activated genes. Interestingly, Gibbs sampling identified no motifs other than the Hrp box. This raises the possibility that $\mathrm{HrpL}$ is the sole regulator of these genes. Reliance on a single regulator and cis regulatory element presumably would enable rapid recruitment into the $\mathrm{HrpL}$ regulon of horizontally acquired effector genes.

The hidden Markov and weight matrix models generate independent lists of candidate promoters ranked by descending scores, which can be further analyzed for likelihood of activity based on genomic context. All of the experimentally validated Hrp promoters have a hidden Markov model score greater than 10.0 or a weight matrix score greater than 4.0 and a distance between the promoter and apparent start site of less than 220 base pairs. The hidden Markov model is simpler to run, and a cutoff score of 10.0 captures virtually all of the validated Hrp promoters. Importantly, the hidden Markov model identifies several active Hrp promoters that were missed by one or the other of the experimental approaches, and marginal promoters found by bioinformatics are retained on the ranked list for future testing rather than being missed entirely. The overriding advantage of the bioinformatic approach to identification of Hrp promoters in sequenced genomes is that it can be completed in a few days, and the costs are essentially those of genome sequencing, which are dropping dramatically with the development of new technologies (Margulies et al. 2005). A fundamental limitation of the bioinformatic approach is that it misses genes that are indirectly activated by HrpL. Ferreira et al. (2006) provide a bioinformatic flowplan for the identification of Hrp promoters in any sequenced strain of $P$. syringae. Below, we will show the utility of these protocols in the identification of $\mathrm{Hrp}$ promoters in $P$. syringae pv. phaseolicola $1448 \mathrm{~A}$ and $P$. syringae pv. syringae B728a.

\section{Extensive testing \\ of potential $P$. syringae pv. tomato DC3000 T3SS substrates validates the bioinformatic approach to identifying effector genes.}

Analyses of the P. syringae pv. tomato DC3000 genome during the draft phase revealed that many effector genes could be predicted by their linkage with Hrp promoters and possession of characteristic patterns in the N-terminal 50 amino acids of the encoded proteins (Fouts et al. 2002; Guttman et al. 2002; Petnicki-Ocwieja et al. 2002). Three of these patterns have been widely used to predict $P$. syringae effectors: i) a serine content of at least $10 \%$, ii) certain aliphatic amino acids in position three or four, and iii) a lack of acidic amino acids in the first 12 residues. Chang et al. (2005) and Schechter et al. (2006) take two different approaches to experimentally validating a comprehensive inventory of effectors in the completed genome of DC3000. The former report tests whether highprobability candidate effectors expressed from their native promoters on a multicopy plasmid can translocate functional levels of C-terminally-fused $\Delta 79$ AvrRpt2. Importantly, this approach seeks evidence that native promoters are strong enough to support delivery of their respective effectors. The latter report tests the ability of 44 candidates that have varying probabilities of being effectors to translocate the Cya (Bordetella pertussis adenylate cyclase) reporter into plant cells when expressed from a tac vector promoter. An important goal of this report is to step outside the circle of expectations regarding $P$. syringae effectors and seek novel effectors based on potential eukaryote biochemical activities or linkage with known effector genes despite the lack of Hrp promoters and known targeting patterns. Also, important is the independent report by Vinatzer et al. (2005) validating translocation of seven of the high-probability effectors in DC3000.

In general, these studies corroborated previous bioinformaticbased predictions and observations (Fouts et al. 2002; Guttman et al. 2002; Petnicki-Ocwiega et al. 2002; Schechter et al. 2004; Zwiesler-Vollick et al. 2002). However, the negative results are particularly interesting. First, no evidence was found for a novel class of effectors expressed independently of the T3SS or lacking the targeting-associated patterns (Schechter et al. 2006; Vinatzer et al. 2005). Second, a subset of the DC3000 effector genes are functionally inactive because of mobile genetic element insertions or other mutations that disrupt either their expression (tested by real-time PCR), their integrity, or the translocation of their products (tested as tac-driven Cya fusions) (Schechter et al. 2006). Third, some of the effector/Hop proteins that have validated Hrp promoters and deliver tac-driven Cya fusions fail to translocate functional levels of $\Delta 79$ AvrRpt 2 when expressed from their native promoter (Chang et al. 2005). In summary, these observations indicate that the bioinformatic approach can identify virtually all of the effector genes in a $P$. syringae genome, but not all of these genes are functional.

With more than 50 genes encoding Hop/effectors in $P$. syringae pv. tomato DC3000 (Table 1), functional classification, 
nomenclature, and bases for research prioritization become important issues. Here, it is useful to revisit three terms that have been used for $P$. syringae T3SS-substrates: effector, Hop, and helper. The term "effector" is prevalent because it applies to all pathogens and to the largest class of proteins traveling the T3SS for most pathogens. True effectors are considered to have their primary action within host cells (Cornelis and Van Gijsegem 2000), whereas helper (accessory) proteins appear to act at the interface between host and parasite in support of the T3SS pathway (Collmer et al. 2002). The HrpA pilin clearly has such a role, but HrpK and harpins are also thought to be helpers. Terms such as Yop (Yersinia outer protein) and Hop have the advantage of applying to both helpers and true effectors, and of course, they provide three-letter designations for naming bacterial genes (Lindeberg et al. 2005). Nevertheless, because the vast majority of Hops appear to be true effectors and the term effector is so widely recognized, we will use this term primarily as we turn to the issue of candidates that fail expression or translocation tests and to the possibility of false positives in the DC3000 effector inventory.

There are several reasons why candidates can fail translocation tests. First, helper proteins expressed from their native promoter appear not to efficiently translocate the $\Delta 79$ AvrRpt2 reporter (Chang et al. 2005). However, this test may not reliably differentiate helpers and true effectors. For example, HopP1- 7 79AvrRpt2 passes this translocation test, but HopP1 has many properties of harpins: the N-terminal half of the protein is highly similar to the HrpW1 harpin, the C-terminal half has a lysozyme-like lytic transglycosylase domain, and the isolated protein can elicit the HR when infiltrated into the apoplast of tobacco leaves (A. R. Ramos and A. Collmer, unpublished data). Resolving these uncertainties will ultimately require a better understanding of the function and site of action of harpins and other putative helper proteins. Second, some effector genes in DC3000 do not appear to be expressed or their proteins do not pass any T3SS substrate tests. However, these proteins are all members of validated Hop/effector families (Table 1). Given that loss of gene function can be important in virulence evolution and that effector loss could potentially expand or shift host range, these inactive effectors (appropriately noted as such) are an important part of the inventory. Third, although the native-promoter $\Delta 79 \mathrm{AvrRpt} 2$-reporter test provides useful clues as to which effectors are most abundantly translocated, it cannot be used alone to determine what is or is not an effector or whether an effector is delivered at levels needed for its own function. In essence, the assay determines whether enough $\triangle 79$ AvrRpt 2 is delivered to elicit an RPS2-dependent HR (Chang et al. 2005; Mudgett et al. 2000). However, as discussed further by Schechter et al. (2006), some effectors may interfere with HR elicitation, the assay does not determine whether a test effector is delivered at a level needed for its own activity (as opposed to the activity of AvrRpt2), and some effectors that are known to be active in DC3000 do not pass this test (Chang et al. 2005).

Table 1 contains a complete list of the 53 T3SS effector and helper genes in $P$. syringae pv. tomato DC3000, including those that appear inactive. The Hop names in Table 1 reflect unified nomenclature recommendations (Lindeberg et al. 2005), and further documentation for all of the data in the table is provided by Schechter et al. (2006) and in the Hop database maintained at the Pseudomonas-Plant Interaction website. Effector genes associated with $a v r$ designations are members of established effector families that were typically founded using strains other than DC3000. It is important to note that every effector/Hop family has at least one member in some $P$. syringae strain that is HrpL-regulated and shown to travel the
T3SS pathway, as stipulated by the unified Hop nomenclature guidelines (Lindeberg et al. 2005). This requirement is important because it eliminates false positives that may pass T3SS substrate tests. False positives potentially could be found in the flagellar proteins, which travel the flagellar biogenesis T3SS and have the same targeting-associated N-terminal amino-acid patterns as $P$. syringae effectors. Interestingly, flagellar genes are downregulated when the Hrp T3SS is activated (Ferreira et al. 2006; Lan et al. 2006). False positives in T3SS translocation tests can also be obtained with Cya reporter fusions involving N-terminal fragments rather than complete test proteins (L. M. Schechter, unpublished results). In summary, we think that the effector inventory for DC3000 is substantially complete and does not contain any false positives. However, as discussed further below, mutant phenotypes are ultimately needed to validate the arsenal of effectors that are active in interactions with a given plant.

\section{The techniques honed with $P$. syringae pv. tomato DC3000 have been extended to the HrpL regulons and effector inventories of $P$. syringae pv. phaseolicola 1448A and $P$. syringae pv. syringae $\mathrm{B} 728 \mathrm{a}$.}

$P$. syringae pv. phaseolicola $1448 \mathrm{~A}$ provided an ideal case for the test by Vencato et al. (2006) of the ability of the bioinformatic methods developed with DC3000 to work in another sequenced strain; 1448A is in a different pathovar and phylogenetic clade and its effector inventory was independently assessed by near-saturation DFI screening and $\Delta 79$ AvrRpt2 reporter translocation assays (Chang et al. 2005). The bioinformatic and DFI screens yielded essentially congruent results for strongly expressed Hrp promoters, but differences occurred with weaker or atypical Hrp promoters. For example, two atypical promoters detected by the DFI screen were below the hidden Markov model high-probability cutoff (although they were above the cutoff for the weight matrix model). In contrast, the DFI screen failed to detect several high-probability Hrp promoters (subsequently validated by real-time PCR), including those for two novel effectors and the 1448A ApbE protein whose ortholog in DC3000 was shown to contribute to bacterial growth in planta (Vencato et al. 2006). Subsequent identification of effector genes within the 1448A HrpL regulon based on targeting-associated patterns also yielded similar results. However, it is important to note that hop $A V 1_{\mathrm{Pph} 1448 \mathrm{~A}}$ and hop $A W 1_{\mathrm{Pph} 1448 \mathrm{~A}}$ were two effector genes found by Chang et al. (2006) that were missed during an initial draft-phase analysis of the 1448A genome because GLIMMER failed to identify the open reading frames (ORF). In general, correct identification of start codons, particularly in genomic islands, is a limiting factor in analyzing potential N-terminal targeting-associated patterns (Vencato et al. 2006). The effector inventory for $P$. syringae pv. phaseolicola $1448 \mathrm{~A}$ is presented in Table 1 .

The annotation of the $P$. syringae pv. syringae B728a genome emphasized factors underlying the epiphytic fitness of this strain rather than the HrpL regulon and effector genes (Feil et al. 2005). However, Greenberg and Vinatzer (2003) have contributed important analyses of the effector inventory of B728a (as well as DC3000), including recent demonstration of the T3SS-dependent translocation of four novel B728a effectors (Vinatzer et al. 2005). To enable comparisons of the HrpL regulons of all three of the sequenced $P$. syringae strains, we used the standardized bioinformatic protocol described by Ferreira et al. (2006) and Vencato et al. (2006) to produce equivalent data for $P$. syringae pv. syringae $\mathrm{B} 728 \mathrm{a}$. We also analyzed downstream ORFs for any candidate effectors based on N-terminal targeting-associated patterns additional to those 
previously noted (Greenberg and Vinatzer 2003; Vinatzer et al. 2005). Table 1 presents the current inventory of effector genes in $P$. syringae pv. tomato DC3000, $P$. syringae pv. phaseolicola $1448 \mathrm{~A}$, and $P$. syringae pv. syringae $\mathrm{B} 728 \mathrm{a}$.

\section{The effector inventories of $P$. syringae pv. tomato $\mathrm{DC} 3000$, $P$. syringae pv. phaseolicola 1448 A, and $P$. syringae pv. syringae $\mathbf{B 7 2 8 a}$ reveal that the active effectors are substantially different in each strain and many effector genes appear inactive.}

In analyzing Table 1 , it is important to remember that many genes are placed in the effector inventory of a given strain through homology-based membership in an Avr or Hop family that was founded in another strain and may be active only in other strains (Lindeberg et al. 2005). Interestingly, all three of the sequenced strains contain several effector genes that appear to be inactive because of lack of a Hrp promoter, mobile element insertion, or frameshift mutation. These genes are colorcoded blue in Table 1. Visualizing the pattern of blue and blank boxes against the background of boxes with likely-active effectors in Table 1 affords several observations. For example, $P$. syringae pv. syringae $\mathrm{B} 728$ a has substantially fewer effectors (active or inactive) than the other two strains. Does this reflect an adaptation of B728a for epiphytic rather than endophytic growth? Or do the necrosis-inducing, pore-forming toxins of B728a substitute for some effector functions? In contrast, $P$. syringae pv. tomato DC3000 has substantially more effectors than the other two strains. This may underlie the ability of DC3000 to attack hosts in two different plant families. Regarding host range, it is interesting that there is relatively little overlap in the effector arsenals of $P$. syringae pv. phaseolicola $1448 \mathrm{~A}$ and $P$. syringae $\mathrm{pv}$. syringae $\mathrm{B} 728 \mathrm{a}$ although they are both pathogens of bean; HopAE1 is the only effector family that is present in both of these strains but lacking in DC3000. It is also striking that the T3SS helper families are more universally distributed in $P$. syringae strains than the effector families. In fact, it appears that only the AvrE1, HopI1, HopX1, Hop AB, and HopAF1 effector families are actively deployed in all three strains (the HopMI family is questionable because hopMI $I_{\mathrm{Pph} 1448 \mathrm{~A}}$ has a $\mathrm{C}$-terminal truncation). But it should also be noted that universally distributed helpers and effectors may have important differences among strains. For example, the HrpA pilin proteins of $P$. syringae pv. tomato and P. syringae pv. syringae belong to different subfamilies and are only 28\% identical (Inoue and Takikawa 2006; Preston et al. 1995), and hopX1 (avrPphE) alleles in P. syringae pv. phaseolicola races differ in their avirulence phenotypes (Stevens et al. 1998). Phylogenetic studies suggest that some effector genes, such as $a v r E$ and $h o p X 1$, are ancient within $P$. syringae, whereas others, such as hopAM1 and hopQ1, have been acquired by more recent horizontal gene transfers into some strains (Deng et al. 2003; Rohmer et al. 2004).

Table 1 also highlights ongoing uncertainties regarding the status of many $P$. syringae effectors, with the yellow boxes indicating conflicting experimental data and the white boxes indicating the lack of tests for active deployment by that strain. Importantly, these assessments are based largely on effector deployment rather than effector function in pathogenesis. Because effectors such as HopAB2 (AvrPtoB) appear to have multiple functional domains (Abramovitch et al. 2003), it is possible that some effectors may be mistakenly predicted to be inactive because of truncations. Furthermore, some effector genes, such as hopWl-1 and hopWl-2 are not obviously disrupted but have much larger homologs in other strains, leaving it unclear whether one form represents an inactive fragment or the other an inactive fusion.
The evidence-coding in Table 1 should help prioritize future efforts to delineate the active arsenal within the total effector inventory of these three model strains. However, understanding the operation of this arsenal in pathogenesis will require additional approaches. For example, we need mutations with lossof-function phenotypes. In this regard, it appears that polymutants lacking combinations of effector genes will be particularly useful. Although mutation of individual effector genes may affect cell-death phenotypes in inoculated plants, mutation of two or more effector genes can substantially reduce growth in planta (Alfano et al. 2000; Badel et al. 2003, 2006; Lin and Martin 2005). Also, we need to better understand effector actions within plant cells with regard to molecular targets, biochemical activities, and parasitic benefit through defense suppression and nutrient release. Two recent reviews summarize exciting progress in this area and highlight effector redundancy at the functional level by noting that multiple effectors contribute to suppressing defense-associated responses, such as papilla formation or cell death in nonhosts (Chisholm et al. 2006; Grant et al., in press).

What forces select for the complex effector arsenals of $P$. syringae strains? An overriding consideration here is that effectors (or more likely their activity) can be detected by the $R$ gene surveillance system, and consequently, many effectors are double agents capable of suppressing defenses in one plant and eliciting them in another (Alfano and Collmer 2004; Espinosa and Alfano 2004; Nomura et al. 2005). Such effector $-R$ gene interactions have long been known to limit $P$. syringae host range at the race-host cultivar level (Keen 1990), but what controls host range at the pathovar-host species level is less clear. A key question is whether the virulence targets of effectors differ among plants. If so, seemingly redundant interdiction of pathways leading to basal defenses could promote a larger host-range and enable basic virulence to be retained even if newly evolved $R$-gene recognition by one of the hosts has selected for loss of one of the effectors. Such an effector loss in the face of $R$-gene selection pressure has recently been documented (Pitman et al. 2005). An alternative (and not mutually exclusive) model is that complexity in the arsenal is driven by the need for interactions among effectors as they coordinately disarm multiple layers of plant defenses. The observation that the loss of hopABl (virPphA) from $P$. syringae pv. phaseolicola 1449B unmasks cryptic avirulence activity of other effectors supports this model. Our growing knowledge of the effector arsenals of three model strains, as summarized in Table 1, provides a foundation for exploring such questions, and it highlights the need for systematic approaches as we explore the functions of this complex system.

\section{Community resources for $\boldsymbol{P}$. syringae effector research can promote the conversion of data to new knowledge.}

The $P$. syringae T3SS effector system is highly complex. We have emphasized above the importance of pattern recognition in dealing with that complexity in the effector discovery process. Here, we will describe resources provided through the Pseudomonas-Plant Interaction website that are intended to help the community manage effector-related data and visualize new biological patterns. In that regard, our experience with effector discovery yielded four practical lessons. First, the development of standard protocols is important to optimize comparisons across effectors and strains. Standardized protocols include bioinformatic methods for identifying Hrp promoters and phylogenomic methods for assigning new hop genes to families and subfamilies as well as assays for translocation and other effector phenotypes (Ferreira et al. 2006; Lindeberg et al. 2005; Schechter et al. 2004). Second, ongoing resolution of ambiguities requires a central, frequently updated dataset with 
evidence-coding and documentation for all data as well as frequent updates of reference files in GenBank and the TIGR Comprehensive Microbial Resource. Third, a unified nomenclature system for effectors and their functions is essential. Fourth, datasets should be easy to manipulate for regrouping and visual coding in the search for new patterns.

Presently, the two primary tools provided through the website are the Hop Database for $P$. syringae pathovars and a downloadable system for viewing Hrp promoters, effector genes, and other virulence-related features in the genome of each of the sequence $P$. syringae strains using the Artemis Genome Viewer. Table 1 represents a small subset of the main Hop database, which now has over 20 fields of information for nearly 300 Hop/effector/helper proteins from many $P$. syringae strains. The dataset is available for anyone to download and use as a platform for analysis or publication. Associated with the database is a standardized system for naming and adding new Hops (Lindeberg et al. 2005). We anticipate that the Hop database will acquire new data fields to accommodate increasing knowledge of effector function. Also, the use of recently developed Gene Ontology terms for the biological processes, molecular functions, and cellular components of effectors will provide a standard vocabulary to enhance the search for patterns in effector function within plants (Gene Ontology Consortium 2006).

\section{Conclusions and future challenges.}

Bioinformatic analyses and extensive experimental validation in $P$. syringae pv. tomato DC3000, P. syringae pv. phaseolicola $1448 \mathrm{~A}$, and $P$. syringae pv. syringae $\mathrm{B} 728 \mathrm{a}$ have established that the vast majority of T3SS effector genes in $P$. syringae are downstream of high-probability Hrp promoter sequences and possess $\mathrm{N}$-terminal targeting-associated patterns. The effector inventories in each strain contain a complex mix of Hop effectors and helpers, and each strain also carries several inactive effector genes (in families validated in other strains). Although active members of five of the seven helper families appear to be present in each strain, only five of the 46 effector families that are represented in these three strains have an active member in all of the strains. Technological advances that are dramatically reducing the cost of DNA sequencing should enable these bioinformatic methods to efficiently reveal the effector gene inventories of a wider array of strains. A larger collection of analyzed strains can reveal patterns of effector distribution that yield insights into $P$. syringae evolution and host-range determination as well as amino-acid patterns within effector families that predict domains and active sites underlying effector functions in plants (Rohmer et al. 2004).

Many questions still remain regarding the deployment and action of the effector arsenal. How are effectors targeted to the T3SS pathway? How does the pathway apparently sort helper proteins to the apoplast and true effectors to the plant cell cytoplasm? Are the many helpers and effectors delivered in some order? What role do effectors play in the host specificity of $P$. syringae pathovars for different plant species and families? Do the large effector complexes of $P$. syringae strains function more as a coordinated system in defeating multilayered plant defenses or as a redundant assemblage of independent factors interacting with plant populations? The establishment of a suite of resources for discovering and categorizing effectors should enable these and many more questions addressing $P$. syringae effector arsenals to be studied in a systematic way.

\section{ACKNOWLEDGMENTS}

This work was supported by the National Science Foundation Plant Genome Research Program Cooperative Agreement DBI-0077622. C. R.
Myers acknowledges support from the United State Department of Agriculture-Agricultural Research Service under Specific Cooperative Agreement 5819074428 as part of project 1907-21000-009-00.

\section{LITERATURE CITED}

Abramovitch, R. B., Kim, Y. J., Chen, S., Dickman, M. B., and Martin, G. B. 2003. Pseudomonas type III effector AvrPtoB induces plant disease susceptibility by inhibition of host programmed cell death. EMBO (Eur. Mol. Biol. Organ.) J 22:60-69.

Alfano, J. R., and Collmer, A. 2004. Type III secretion system effector proteins: Double agents in bacterial disease and plant defense. Annu. Rev. Phytopathol. 42:385-414.

Alfano, J. R., Charkowski, A. O., Deng, W.-L., Badel, J. L., PetnickiOcwieja, T., van Dijk, K., and Collmer, A. 2000. The Pseudomonas syringae Hrp pathogenicity island has a tripartite mosaic structure composed of a cluster of type III secretion genes bounded by exchangeable effector and conserved effector loci that contribute to parasitic fitness and pathogenicity in plants. Proc. Natl. Acad. Sci. U.S.A. 97:4856-4861.

Badel, J. L., Nomura, K., Bandyopadhyay, S., Shimizu, R., Collmer, A., and He, S. Y. 2003. Pseudomonas syringae pv. tomato DC3000 HopPtoM (CEL ORF3) is important for lesion formation but not growth in tomato and is secreted and translocated by the Hrp type III secretion system in a chaperone-dependent manner. Mol. Microbiol. 49:1239-1251.

Badel, J. L., Shimizu, R., Oh, H.-S., and Collmer, A. 2006. A Pseudomonas syringae pv. tomato avrE1/hopM1 mutant is severely reduced in growth and lesion formation in tomato. Mol. Plant Microbe Interact. 19:99-111.

Buell, C. R., Joardar, V., Lindeberg, M., Selengut, J., Paulsen, I. T., Gwinn, M. L., Dodson, R. J., Deboy, R. T., Durkin, A. S., Kolonay, J. F., Madupu, R., Daugherty, S., Brinkac, L., Beanan, M. J., Haft, D. H., Nelson, W. C., Davidsen, T., Liu, J., Yuan, Q., Khouri, H., Fedorova, N., Tran, B., Russell, D., Berry, K., Utterback, T., Vanaken, S. E., Feldblyum, T. V., D’Ascenzo, M., Deng, W.-L., Ramos, A. R., Alfano, J. R., Cartinhour, S., Chatterjee, A. K., Delaney, T. P., Lazarowitz, S. G., Martin, G. B., Schneider, D. J., Tang, X., Bender, C. L., White, O., Fraser, C. M., and Collmer, A. 2003. The complete sequence of the Arabidopsis and tomato pathogen Pseudomonas syringae pv. tomato DC3000. Proc. Natl. Acad. Sci. U.S.A. 100:10181-10186.

Chang, J. H., Urbach, J. M., Law, T. F., Arnold, L. W., Hu, A., Gombar, S., Grant, S. R., Ausubel, F. M., and Dangl, J. L. 2005. A high-throughput, near-saturating screen for type III effector genes from Pseudomonas syringae. Proc. Natl. Acad. Sci. U.S.A. 102:2549-2554.

Chisholm, S. T., Coaker, G., Day, B., and Staskawicz, B. J. 2006. Host-microbe interactions: Shaping the evolution of the plant immune response. Cell 124:803-814.

Collmer, A., Lindeberg, M., Petnicki-Ocwieja, T., Schneider, D. J., and Alfano, J. R. 2002. Genomic mining type III secretion system effectors in Pseudomonas syringae yields new picks for all TTSS prospectors. Trends Microbiol. 10:462-469.

Cornelis, G. R., and Van Gijsegem, F. 2000. Assembly and function of type III secretory systems. Annu. Rev. Microbiol. 54:735-774.

Deng, W.-L., Rehm, A., Charkowski, A., Rojas, C. M., and Collmer, A. 2003. Pseudomonas syringae exchangeable effector loci: Sequence diversity in representative pathovars and virulence function in $P$. syringae pv. syringae B728a. J. Bacteriol. 185:2592-2602.

Espinosa, A., and Alfano, J. R. 2004. Disabling surveillance: Bacterial type III secretion system effectors that suppress innate immunity. Cell Microbiol. 6:1027-1040.

Feil, H., Feil, W. S., Chain, P., Larimer, F., Dibartolo, G., Copeland, A., Lykidis, A., Trong, S., Nolan, M., Goltsman, E., Thiel, J., Malfatti, S., Loper, J. E., Lapidus, A., Detter, J. C., Land, M., Richardson, P. M., Kyrpides, N. C., Ivanova, N., and Lindow, S. E. 2005. Comparison of the complete genome sequences of Pseudomonas syringae pv. syringae B728a and pv. tomato DC3000. Proc. Natl. Acad. Sci. U.S.A. 102:11064-11069.

Ferreira, A. O., Myers, C. R., Gordon, J. S., Martin, G. B., Vencato, M., Collmer, A., Wehling, M. D., Alfano, J. R., Moreno-Hagelsieb, G., Lamboy, W. F., DeClerck, G., Schneider, D. J., and Cartinhour, S. W. 2006. Whole-genome expression profiling defines the HrpL regulon of Pseudomonas syringae pv. tomato DC3000, allows de novo reconstruction of the Hrp cis element, and identifies novel co-regulated gene. Mol. Plant Microbe Interact. 19:1167-1179.

Fouts, D. E., Abramovitch, R. B., Alfano, J. R., Baldo, A. M., Buell, C. R., Cartinhour, S., Chatterjee, A. K., D'Ascenzo, M., Gwinn, M. L., Lazarowitz, S. G., Lin, N.-C., Martin, G. B., Rehm, A. H., Schneider, D. J., van Dijk, K., Tang, X., and Collmer, A. 2002. Genomewide identification of Pseudomonas syringae pv. tomato DC3000 promoters con- 
trolled by the HrpL alternative sigma factor. Proc. Natl. Acad. Sci. U.S.A. 99:2275-2280.

Gene Ontology Consortium. 2006. The Gene Ontology (GO) project in 2006. Nucleic Acids Res. 34:D322-D326.

Grant, S. R., Fisher, E. J., Chang, J. H., Mole, B. M., and Dangl, J. L. 2006. Subterfuge and manipulation: Type III effector proteins of phytopathogenic bacteria. Annu. Rev. Microbiol. In press.

Greenberg, J. T., and Vinatzer, B. A. 2003. Identifying type III effectors of plant pathogens and analyzing their interaction with plant cells. Curr. Opin. Microbiol. 6:20-28.

Guttman, D. S., Vinatzer, B. A., Sarkar, S. F., Ranall, M. V., Kettler, G., and Greenberg, J. T. 2002. A functional screen for the Type III (Hrp) secretome of the plant pathogen Pseudomonas syringae. Science 295:1722-1726.

Hirano, S. S., and Upper, C.D. 2000. Bacteria in the leaf ecosystem with emphasis on Pseudomonas syringae-A pathogen, ice nucleus, and epiphyte. Microbiol. Mol. Biol. Rev. 64:624-653.

Inoue, Y., and Takikawa, Y. 2006. The hrpZ and $h r p A$ genes are variable, and useful for grouping Pseudomonas syringae bacteria. J. Gen. Plant Pathol. 72:26-33.

Jackson, R. W., Athanassopoulos, E., Tsiamis, G., Mansfield, J. W., Sesma, A., Arnold, D. L., Gibbon, M. J., Murillo, J., Taylor, J. D., and Vivian, A. 1999. Identification of a pathogenicity island, which contains genes for virulence and avirulence, on a large native plasmid in the bean pathogen Pseudomonas syringae pathovar phaseolicola. Proc. Natl. Acad. Sci. U.S.A. 96:10875-10880

Joardar, V., Lindeberg, M., Jackson, R. W., Selengut, J., Dodson, R., Brinkac, L. M., Daugherty, S. C., DeBoy, R., Durkin, A. S., Giglio, M. G., Madupu, R., Nelson, W. C., Rosovitz, M. J., Sullivan, S., Haft, D. H., Creasy, T., Davidsen, T., Zafar, N., Zhou, L., Halpin, R., Holley, T., Khouri, H., Feldblyum, T., White, O., Fraser, C. M., Chatterjee, Cartinhour, S., Schneider, D. J., Mansfield, J., Collmer, A., and Buell, C. R. 2005. Whole genome sequence analysis of Pseudomonas syringae pv. phaseolicola 1448A reveals sequence divergence among pathovars in genes involved in virulence and mobile genetic elements. J. Bacteriol 187:6488-6498.

Keen, N. T. 1990. Gene-for-gene complementarity in plant-pathogen interactions. Annu. Rev. Genet. 24:447-463.

Lan, L., Deng, X., Zhou, J., and Tang, X. 2006. Genome-wide gene expression analysis of Pseudomonas syringae pv. tomato DC3000 reveals overlapping and distinct pathways regulated by $h r p L$ and $h r p R S$. Mol. Plant Microbe Interact. 19:976-987.

Lin, N. C., and Martin, G. B. 2005. An avrPto/avrPtoB mutant of Pseudomonas syringae pv. tomato DC3000 does not elicit Pto-specific resistance and is less virulent on tomato. Mol. Plant-Microbe Interact. 18:43-51

Lindeberg, M., Stavrinides, J., Chang, J. H., Alfano, J. R., Collmer, A., Dangl, J. L., Greenberg, J. T., Mansfield, J. W., and Guttman, D. S. 2005. Proposed guidelines for a unified nomenclature and phylogenetic analysis of type III Hop effector proteins in the plant pathogen Pseudomonas syringae. Mol. Plant-Microbe Interact. 18:275-282.

Marco, M. L., Legac, J., and Lindow, S. E. 2005. Pseudomonas syringae genes induced during colonization of leaf surfaces. Environ. Microbiol. 7:1379-1391

Margulies, M., Egholm, M., Altman, W. E., Attiya, S., Bader, J. S., Bemben, L. A., Berka, J., Braverman, M. S., Chen, Y. J., Chen, Z., Dewell, S. B., Du, L., Fierro, J. M., Gomes, X. V., Godwin, B. C., He, W., Helgesen, S., Ho, C. H., Irzyk, G. P., Jando, S. C., Alenquer, M. L., Jarvie, T. P., Jirage, K. B., Kim, J. B., Knight, J. R., Lanza, J. R., Leamon, J. H., Lefkowitz, S. M., Lei, M., Li, J., Lohman, K. L., Lu, H., Makhijani, V. B., McDade, K. E., McKenna, M. P., Myers, E. W., Nickerson, E., Nobile, J. R., Plant, R., Puc, B. P., Ronan, M. T., Roth, G. T., Sarkis, G. J., Simons, J. F., Simpson, J. W., Srinivasan, M., Tartaro, K. R., Tomasz, A., Vogt, K. A., Volkmer, G. A., Wang, S. H., Wang, Y., Weiner, M. P., Yu, P., Begley, R. F., and Rothberg, J. M. 2005. Genome sequencing in microfabricated high-density picolitre reactors. Nature 437:376-380.

Monier, J. M., and Lindow, S. E. 2003. Differential survival of solitary and aggregated bacterial cells promotes aggregate formation on leaf surfaces. Proc Natl Acad Sci U.S.A. 100:15977-15982.

Mudgett, M. B. 2005. New insights to the function of phytopathogenic bacterial type III effectors in plants. Annu. Rev. Plant Biol. 56:509-531.

Mudgett, M. B., Chesnokova, O., Dahlbeck, D., Clark, E. T., Rossier, O., Bonas, U., and Staskawicz, B. J. 2000. Molecular signals required for type III secretion and translocation of the Xanthomonas campestris AvrBs2 protein to pepper plants. Proc. Natl. Acad. Sci. U.S.A. 97:13324-13329.

Nomura, K., Melotto, M., and He, S. Y. 2005. Suppression of host defense in compatible plant-Pseudomonas syringae interactions. Curr. Opin. Plant Biol. 8:361-368.

Petnicki-Ocwieja, T., Schneider, D. J., Tam, V. C., Chancey, S. T., Shan, L., Jamir, Y., Schechter, L. M., Buell, C. R., Tang, X., Collmer, A., and Alfano, J. R. 2002. Genomewide identification of proteins secreted by the Hrp type III protein secretion system of Pseudomonas syringae pv. tomato DC3000. Proc. Natl. Acad. Sci. U.S.A. 99:7652-7657.

Pitman, A. R., Jackson, R. W., Mansfield, J. W., Kaitell, V., Thwaites, R., and Arnold, D. L. 2005. Exposure to host resistance mechanisms drives evolution of bacterial virulence in plants. Curr. Biol. 15:2230-2235.

Preston, G. M. 2000. Pseudomonas syringae pv. tomato: The right pathogen, of the right plant, at the right time. Mol. Plant Pathol. 1:263-275.

Preston, G., Huang, H.-C., He, S. Y., and Collmer, A. 1995. The HrpZ proteins of Pseudomonas syringae pvs. syringae, glycinea, and tomato are encoded by an operon containing Yersinia ysc homologs and elicit the hypersensitive response in tomato but not soybean. Mol. Plant-Microbe Interact. 8:717-732.

Quirino, B. F., and Bent, A. F. 2003. Deciphering host resistance and pathogen virulence: The Arabidopsis/Pseudomonas interaction as a model. Mol. Plant Pathol. 4:517-530.

Rohmer, L., Guttman, D. S., and Dangl, J. L. 2004. Diverse evolutionary mechanisms shape the type III effector virulence factor repertoire in the plant pathogen Pseudomonas syringae. Genetics 167:1341-1360.

Sarkar, S. F., and Guttman, D. S. 2004. Evolution of the core genome of Pseudomonas syringae, a highly clonal, endemic plant pathogen. Appl. Environ. Microbiol. 70:1999-2012.

Sawada, H., Suzuki, F., Matsuda, I., and Saitou, N. 1999. Phylogenetic analysis of Pseudomonas syringae pathovars suggests the horizontal gene transfer of $\arg K$ and the evolutionary stability of $h r p$ gene cluster. J. Mol. Evol. 49:627-644.

Schechter, L. M., Roberts, K. A., Jamir, Y., Alfano, J. R., and Collmer, A. 2004. Pseudomonas syringae type III secretion system targeting signals and novel effectors studied with a Cya translocation reporter. J. Bacteriol. 186:543-555.

Schechter, L. M., Vencato, M., Jordan, K. L., Schneider, S. E., Schneider, D. J., and Collmer, A. 2006. Multiple approaches to a complete inventory of Pseudomonas syringae pv. tomato DC3000 type III secretion system effector proteins. Mol Plant Microbe Interact. 19:1180-1192.

Stevens, C., Bennett, M. A., Athanassopoulos, E., Tsiamis, G., Taylor, J. D., and Mansfield, J. W. 1998. Sequence variations in alleles of the avirulence gene avrPphE.R2 from Pseudomonas syringae pv. phaseolicola lead to loss of recognition of the AvrPphE protein within bean cells and a gain in cultivar-specific virulence. Mol. Microbiol. 29:165-1677.

Tang, X., Xiao, Y., and Zhou, J.-M. 2006. Regulation of the type III secretion system in phytopathogenic bacteria. Mol. Plant Microbe Interact. 19:976-987.

Thwaites, R., Spanu, P. D., Panopoulos, N. J., Stevens, C., and Mansfield, J. W. 2004. Transcriptional regulation of components of the type III secretion system and effectors in Pseudomonas syringae pv. phaseolicola. Mol. Plant-Microbe Interact. 17:1250-1258.

Vencato, M., Tian, T., Alfano, J. R., Buell, C. R., Cartinhour, S., DeClerck, J., Guttman, D. S., Joardar, V., Lindeberg, M., Mansfield, J., Myers, C. R., Collmer, A., and Schneider, D. J. 2006. The HrpL (type III secretion system) regulon and effector genes of Pseudomonas syringae pv. phaseolicola 1448A. Mol. Plant Microbe Interact. 19:1193-1206.

Vinatzer, B. A., Jelenska, J., and Greenberg, J. T. 2005. Bioinformatics correctly identifies many type III secretion substrates in the plant pathogen Pseudomonas syringae and the biocontrol isolate $P$. fluorescens SBW25. Mol. Plant Microbe Interact. 18:877-888.

Zwiesler-Vollick, J., Plovanich-Jones, A. E., Nomura, K., Brandyopadhyay, S., Joardar, V., Kunkel, B. N., and He, S. Y. 2002. Identification of novel hrp-regulated genes through functional genomic analysis of the Pseudomonas syringae pv. tomato DC3000 genome. Mol. Microbiol. 45:12071218

\section{AUTHOR-RECOMMENDED INTERNET RESOURCE}

Pseudomonas-Plant Interaction website: pseudomonas-syringae.org 